\title{
PRIMER PRIMITIVNEGA SREDNJEVEŠKEGA VEČGLASJA IZ KRANJA
}

\author{
Janez Höfler (Ljubljana)
}

Splošna razvojna slika, ki jo daje zgodovina evropske glasbene kulture, je zgrajena le na temelju velikih, razvojno pomembnih in bolj ali manj edinstvenih dosežkov. Zato seveda ne nudi prav močne opore pri raziskovanju in opredeljevanju obrobnega, v provincialno zatišje omejenega glasbenoumetnostnega dogajanja. To velja tembolj za starejša zgodovinska obdobja, ko so bile možnosti izmenjavanja na tem področju skromnejše in je bil razvoj še preveč odvisen od regionalno pogojenih in samim sebi zadostnih estetskih norm, pri izoblikovanju katerih je v veliki meri sodelovala tudi razslojenost in idejna raznolikost nosivcev glasbene kulture.

Pred nami je eno izmed zagonetnih vprašanj takšne vrste, ki ga zastavlja doslej edini znani primer srednjeveškega večglasja na Slovenskem. To je triglasni zapis začetka prve božične lekcije Primo tempore, ki je na prvem listu kranjskega župnijskega breviarija iz prve polovice 15. stol.; hrani ga Nadškofijski arhiv v Ljubljani (sign. 154 a). ${ }^{1}$ Notiran je v obliki partiture in $\mathrm{v}$ neritmični gotski koralni notaciji, v zelo bežni in nedoločeni kurzivni obliki. Sestavljen je iz dveh delov, iz prošnje za blagoslov Jube, domne, benedicere in iz prve vrstice lekcije Primo tempore alleviata est terra Zabulon \& terra Nephtali. Naslednje tri vrstice so zapisane v spodnjem desnem prostoru in brez glasbe, po tedanjem običaju pa so se seveda pele po melodičnem stavku prve, kar je bilo tudi z drugimi vrsticami lekcije. Na prvi pogled je razvidno, da je ta kranjski večglasni zapis zabeležen površno in komaj dovoljuje enoumno moderno transkripcijo. Vendar je ob upoštevanju pravil, ki veljajo za gotsko (rombsko) koralno notacijo in jih naš primer komaj nakazuje, mogoče rekonstruirati približno notno podobo. Ta sestoji iz začetkov $\mathrm{v}$ vzporednih kvintah in oktavah in se nato razrase $\mathrm{v}$ zamotane in le s težavo določljive harmonske komplekse. V osnovnem obrisu gre za zelo arhaičen triglasen paralelni organum, kot ga poznamo iz znamenitega, dolgo časa menihu Hucbaldu pripisovanega rokopisa Musica enhiriadis iz 9. stol., nanj pa se navezuje prosta vokalizacija. Tudi ta ne kaže konsonančnih harmonskih postopov napredne pozne gotike, temveč se omejuje na tvorbe, značilne za primitivni neritmični večglasni conductus, na temelju praznih kvint in oktav in $z$ neizogibnimi spremljajočimi disonancami.

${ }_{1}$ Prvič omenjen v avtorjevi razpravi Gorenjski prispevki $k$ najstarejši glasbeni zgodovini na Slovenskem, Kronika XIV, 1966, 98 s., žal pod napačno signaturo 743. 
Pojav tako konservativnega večglasja v prostoru, ki v bistvu spada v srednjeevropski okvir, in $\mathrm{v}$ času, ko so se naprednejša področja zahodne Evrope že pripravljala na razvoj zgodnjerenesančne polifonije, nujno sega $\mathrm{v}$ jedro problematike srednjeveškega večglasja. Vendar pokaže pregled ustrezne situacije $\mathrm{v}$ drugih področjih srednje Evrope, da naš primer ni niti izjemen niti tako osamljen, temveč se $\mathrm{v}$ določeni meri logično vključuje $\mathrm{v}$ splošno srednjeveško večglasno prakso. $\mathrm{Na}$ vprašanja primitivnega večglasja tega širokega prostora so pravzaprav opozorili že vsi pomembni raziskovavci srednjeveškega večglasja, ki so se bolj ali manj omejevali na napredne francoske oblike (npr. Friedrich Ludwig, ${ }^{2}$ Jacques Handschin,, ${ }^{3}$ Marius Schneider. ${ }^{4}$ ). Ta tema je postala še bolj pereča takrat, ko so se začela podrobneje raziskovati tista področja, ki so premogla samo takšno primitivno obliko večglasja, med njimi nam sosednja ozemlja. Štajerske primere je obdelal Hellmut Federhofer, ${ }^{5}$ podobno situacijo so odkrile raziskave na Madžarskem, ${ }^{6} \mathrm{ki}$ se jim pridružujejo tudi primeri iste vrste na Češkem in Hrvaškem, oz. natančneje v zagrebški stolnici. ${ }^{7}$ Dragocen in nepogrešljiv pripomoček $\mathrm{s}$ podrobnim katalogom ohranjenih virov, ki je sumarično podal problematiko tega glasbenoumetnostnega področja za nemško govoreče ozemlje, pa je izpod peresa Arnolda Geeringa. ${ }^{8}$ Ta študija je na temelju vsega znanega in dosegljivega gradiva tega ozemlja razjasnila marsikatero vprašanje glede geografske razprostranjenosti, značilnosti časovnih okvirov in stilnih razsežnosti in zato predstavlja trdno oporo pri opredeljevanju in ocenjevanju tistih primerov, ki niso v njej zajeti. Poleg čeških, madžarskih in hrvaških sodi med te primere tudi omenjeni primer iz Kranja.

Kot je pokazala Geeringova študija, gre pri tej konservativni tradiciji srednjeveškega večglasja v bistvu za dve smeri, za paralelni oz. prosti organum in za večglasni conductus. Prvi se nanaša na stroga obredna besedila, ki so bila po tedanjem običaju pogosto tropirana, drugi na psevdoliturgično ali sploh neliturgično cerkveno latinsko liriko. Za oba je, $\mathrm{v}$ nasprotju $\mathrm{z}$ naprednim motetom, značilno bolj ali manj enako gibanje $v$ vseh glasovih (homofonija) in isto besedilo. Med liturgičnimi besedili tvorijo posebno skupino lekcije za slovesno mašno in nočno kanonično obredje, med katere sodi tudi naš primer. V oficiju se večglasne kompozicije te vrste pojavljajo $\mathrm{v}$ božičnih jutranjicah. Tu sta najpogostejša prva in druga lekcija za prvi nokturn (Primo tempore alleviata est terra in Consolamini popule meus), medtem ko sta naslednji dve znani le v enem, tudi za nas

2 Die Quellen der Motetten des ältesten Stils, v: AfMw V, 1923, 185 ss; Die mehrstimmigen Werken der Handschrift Engelberg 314, v: KJ XXI, 1908, 48 ss.

${ }^{3} \mathrm{Zu}$ den »Quellen der Motetten des ältesten Stils«, AfMw VI, 1924, 245 ss.

${ }_{4}$ Geschichte der Mehrstimmigkeit II, Berlin 1935.

5 Zur Pflege mittelalterlicher Mehrstimmigkeit im Benediktinerstift St. Lambrecht, Anzeiger der phil.-hist. Klasse der Österr. Akad. der Wissensch., 1947, Nr. 21; Eine neue Quelle zur Organumpraxis des späten Mittelalters, Acta musicologica XX, 1948; Ein Beispiel spätmittelalterlicher Organumspraxis in Vorau, Cod.22, Aus Archiv und Chronik, III, Graz 1950.

6 Rajeczky B., Spätmittelalterliche Organalkunst in Ungarn, Studia Musicologica (Budapest), zv. I, 1961.

7 Szigeti K., Mehrstimmige Gesänge aus dem 15. Jh. im Antiphonale des Oswald Thuz, Studia Musicologica (Budapest), zv. VI, 1964.

8 Die Organa und mehrstimmigen Conductus in den Handschriften des deutschen Sprachgebietes vom 13. bis. 16. Jh., Publikationen der Schweizerischen musikforschenden Gesellschaft, Serie II Vol. I, Bern 1952. 

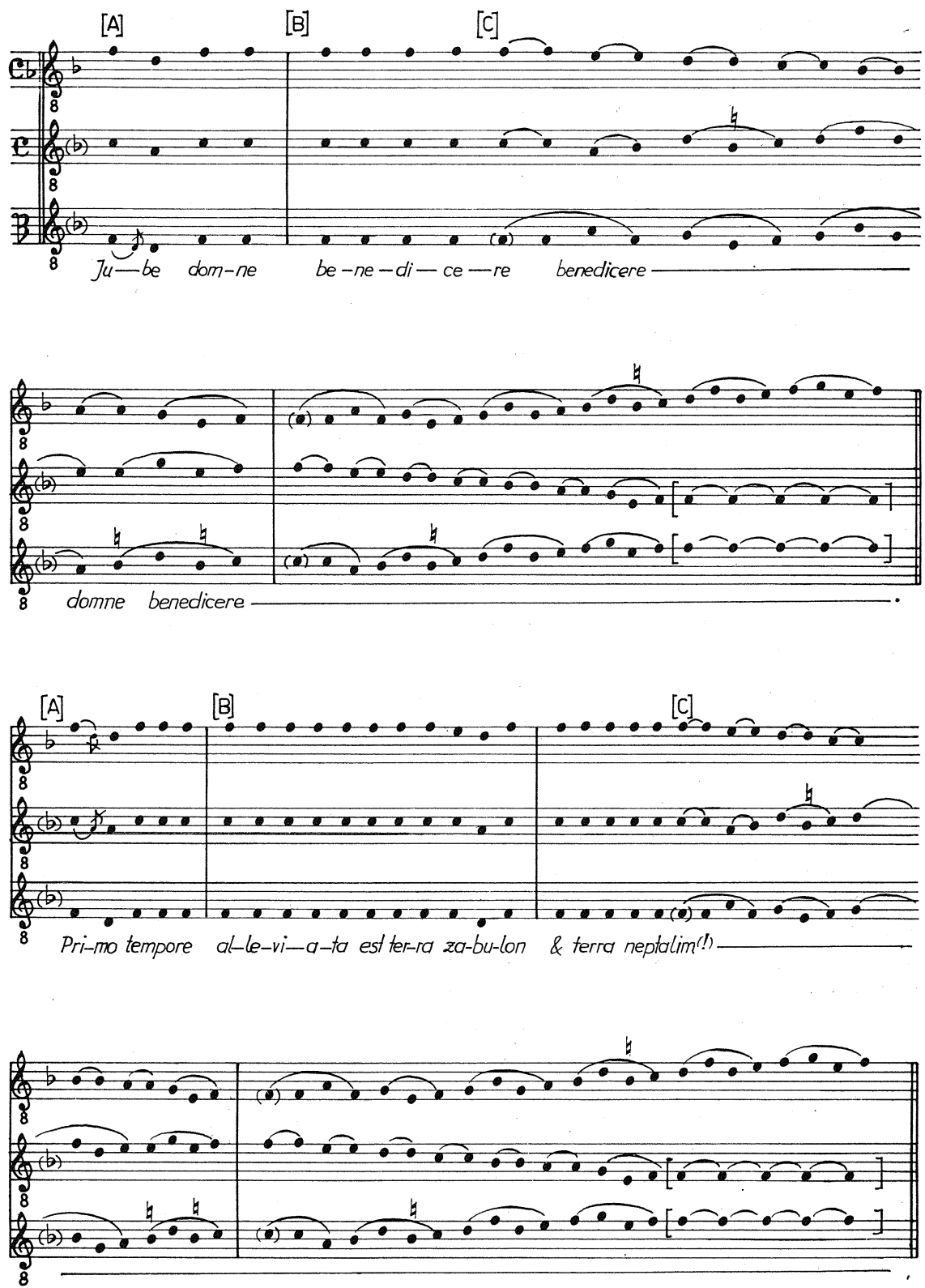
pomembnem viru (dvodelni antifonarij iz samostana St. Lambrecht na avstrijskem Štajerskem, zdaj v graški Univerzitetni knjižnici s sign. Ms. III 29 in 30). Vsako teh lekcij uvaja prošnja za blagoslov Jube, domne, benedicere, ki je pogosto tropirana, tako da lahko predstavlja samostojni prvi verz lekcije.

$\mathrm{V}$ nemškem prostoru obstoje štiri različne večglasne kompozicije prve božične lekcije $\mathrm{v}$ devetih zapisih. Od teh sta dve triglasni (Engelberg, iz. 1.1372 in fragment neznane južnonemške provenience, konec 15. stol., iz zapuščine J. Wolfa). ${ }^{9} \mathrm{~V}$ primeri $\mathrm{z}$ njimi je tudi kranjski primer kljub svojemu neuglednemu zapisu zaključena in samostojna kompozicija. Pozornost vzbuja že začetek v paralelnem organumu $\mathrm{v}$ recitativnih obrazcih (odstavka $\mathrm{A}$ in $\mathrm{B}$ ), ki služi za slovesno podajanje besedila, katerega učinek je še stopnjevan s triglasjem. Arnold Geering je v svojem omenjenem pregledu navedel, da med nemškimi kompozicijami vseh vrst primitivnega večglasja ni niti enega primera čistega paralelnega organuma. $\mathrm{S}$ tem nikakor ni rečeno, da $\mathrm{v}$ srednjeevropski večglasni praksi tega časa ne bi obstajal, temveč, da so ga $\mathrm{v}$ glavnem le improvizirali in zapisovali samo $\mathrm{v}$ učne namene.10 Zagovorniki hipoteze, da poznejšemu zahodnoevropskemu večglasju tako tuji paralelni organum ni bil le teoretična postavka, temveč živa in uporno trajajoča srednjeveška praksa, bodo $\mathrm{v}$ naši kompoziciji imeli dober dokaz za to. Kranjski primer takšno prakso ne le potrjuje, temveč jo kaže celo $\mathrm{v}$ slovesnejši triglasni obliki in $\mathrm{v}$ neposredni povezavi $\mathrm{z}$ nekoliko naprednejšim stavkom večglasnega conductusa, ki ga predstavlja obširna in zanesena sklepna vokalizacija.

Da je kranjska večglasna božična lekcija ne stihijsko, temveč razumsko komponirana, je razvidno razen iz enotnega tipa recitativnega organuma predvsem iz strukture sklepne vokalizacije. Ob zaključku prošnje Jube, domne zapisan stavek se ob koncu prve vrstice dosledno ponovi. V tem je dokaz, da je zabeležena kompozicija dovršena in ne fragmentarna. Vokalizacija je sestavljena iz dveh delov, katerih drugi vsebuje iste melodične postope kot prvi, le da so prestavljeni iz zgornjega glasu v srednji, iz srednjega $v$ spodnji in iz spodnjega glasu v zgornji glas, ki ima še zaključni rep. Prvi del vokalizacije kadencira na toniki v ustrezni oktavi s kvinto, celotna vrsta pa se zaključi prav tako na toniki, toda $\mathrm{v}$ prazni oktavi s podvojeno zgornjo. $\mathrm{S}$ tem je doseženo značilno raznotežje med obema kadencama, srednjo in sklepno. Najbrž ni preveč tvegano misliti, da je za organum značilni osnovni glas (vox principalis) po stari organalni praksi $\mathrm{v}$ spodnjem glasu kompozicije.

S temi nekaj značilnostmi predstavlja kranjska večglasna kompozicija iz prve polovice 15. stol. droben, a zgovoren primer srednjeevropske srednjeveške večglasne prakse, ki se je ponavljala ob slovesnejših in liturgično strožjih priložnostih. S podrobnejšim vrednotenjem kompozicije bi že zašli v problematiko, ki je splošnega pomena za ta arhaični slogovni izraz in bi presegla naš regionalni okvir. Vendar lahko zapišemo, da je kljub svoji konservativnosti $\mathrm{v}$ primeri $\mathrm{z}$ naprednim zahodnoevropskim večglasjem dokaz določene, $v$ svoje zakonitosti in v svoja merila zaprte glasbene estetike.

9 Geering A., op. cit., 31. Od ostalih lekcij je znan samo še en triglasni primer druge lekcije (Trier, konec 15. stol., Geering, ib.), ki se mu pridružuje še ena triglasna kompozicija iste vrste iz Zagreba (Szigeti, ib.).

$10 \mathrm{Ib}, \mathrm{,}, 45$. 


\section{SUMMARY}

The composition of the first Christmas lection Jube, domne, benedicere, for three voices written in Hufnagelschrift on the first leaf of a breviary from the parish of Kranj (first half of the fifteenth century, now housed in the archbishop's archives in Ljubljana) is still the only known example of Medieval polyphony in Slovenia. According to its stylistic characteristics, it belongs to the sphere of Central European primitive polyphony which in the form of organum and conductus, survived throughout the 15 th and even into the beginning of the 16th century. The closest examples of such a polyphony come from the monasteries of St. Lambrecht and Seckau in Styria and from Zagreb cathedral (second half of the 15th century). The Kranj example reveals the essential features of this primitive type of medieval polyphony; yet it also shows some interesting and particular details. Remarkable is its rational construction which has a basic recitative nucleus in a parallel organum and concluding vocalization in the style of the simple conductus (note against note). 